\title{
A Severe Intracranial and Extracranial Complications of The Middle Ear Cholesteatoma (A Report Case)
}

\author{
Adouly T*, Adnane C, Taali L, Barhmi I, Rouadi S, Abada R, Roubal M and Mahtar M
}

Department of ENT, 20 Aout hospital. Ibn Rochd University Hospital, Casablanca, Morocco

${ }^{*}$ Corresponding author: Adouly T, Department of ENT, 20 Aout hospital, Ibn Rochd university hospital, Casablanca, Morocco, E-mail: adouly.taoufik@gmail.com

Citation: Adouly T, Adnane C, Taali L, Barhmi I, Rouadi S, et al. (2015) A Severe Intracranial and Extracranial Complications of The Middle Ear Cholesteatoma (A Report Case). J Case Rep Stud 3(2): 202. doi: 10.15744/2348-9820.2.502

Received Date: December 21, 2014 Accepted Date: March 27, 2015 Published Date: April 07, 2015

\begin{abstract}
Otological intracranial and extracranial complications are still a major problem and a life-threatening complication of otitis media mainly cholesteatoma. We present a case of a 40-year-old man, who presented mastoiditis with large subperiosteal abscess, repeated headache and acutely altered mental status, caused by subdural abscess. CT scan was done first to confirm the diagnosis, secondly to monitor the evolution. The intracranial collection was drained and the cholesteatoma was removed by mastoidectomy. The patient was still free of symptoms after 12 months. The clinical characteristics and treatment of this disease remain controversial; this case report highlights the epidemiological, clinical and radiological aspects of intracranial and extracranial complications of the middle ear cholesteatoma.
\end{abstract}

Keywords: Subperiosteal abscess; Mastoiditis; Complication; Cholesteatoma; Surgery

\section{Background}

A middle ear cholesteatoma is a dangerous pathology, because it leads to intra and extracranial complications which are fatal [1]. The development and appropriate use of antibiotics have led to a decrease in these potentially devastating complications mainly acute mastoiditis with an incidence as low as $0.004 \%$ in the 1980 [2]. Nevertheless, there are still a number of patients who develop acute mastoiditis, subperiosteal abscess, facial palsy, and intracranial complication due to recent increase of antibiotic-resistant bacteria [3]. Here, we report a case of acute mastoiditis associated with subperiosteal and subdural abcess following chronic otitis media in order to analyze management of the disease, and review its literature.

\section{Case report}

A 40-year-old male, was admitted to ENT Department of the 20 Aout hospital, Ibn Rochd university hospital, with large mastoiditis of the right ear, otalgia, fever, severe headache and nausea. He also had intermittent otorrhea, hearing impairment from right ear with mild dizziness for the past two years. The patient denied any history of diabetes mellitus, hypertension, or pulmonary tuberculosis. On clinical examination, he had $39.50{ }^{\circ} \mathrm{C}$, tachycardia $(110 \mathrm{beats} / \mathrm{min})$, respiratory rate $30 / \mathrm{minute}$ and blood pressure 140/90 mm Hg. The patient appeared in a state of stupor. There were no signs of meningeal irritation and fundus examination was normal. Otoscopic examination revealed right purulent foul smelling discharge with granulation and epithelial desquamation, giving the presumptive diagnosis of attic cholesteatoma of the right ear. Also, a large swelling of postauricular area (mastoiditis) was identified. Left ear, nose, and throat were normal. His cardiovascular, respiratory and abdominal examinations were normal. Furthermore, lumbar puncture was normal. Pure-tone audiometry revealed conductive type hearing loss of right ear (air conduction; $65 \mathrm{~dB}$, bone conduction; $20 \mathrm{~dB}$ ). His investigations revealed white blood cell count 18500/mm3, with neutrophil count $75 \%$.

Cerebral CT and temporal bone CT scans were performed to find the cause of altered mental state. Temporal bone CT scan revealed soft tissue density filling the middle ear cavity, and a decreased aeration of ipsilateral mastoid cells; with huge subperiosteal abscess in the right postauricular area measuring $98 \mathrm{~mm} \times 24 \mathrm{~mm} \times 70 \mathrm{~mm}$ (Figure 1). Cerebral Computed tomography showed acute mastoiditis and subperiosteal abscess with communication to an extra axial collection, measuring $1.6 \times 2 \times 1.8 \mathrm{~cm}$, on right side of the brain through a bony defect at the right temporal bone suggesting a subdural abscess (Figure 2).

The patient underwent drainage of mastoiditis under local anesthesia (Figure 3). The surgical neurology decision was temporal craniotomy with drainage of abscess. The capsule of the collection was exposed and incised. The bacterial culture revealed the presence of Staphylococcus aureus. Patient was started on Ceftriaxone 2g daily, Metronidazole $500 \mathrm{mg} 3$ times per day IV, with steroids and diuretics. Duration of antibiotic was 6 weeks. There was a general improvement with decreasing temperature and imp- 
rovement of consciousness. Otologic surgery (right mastoidectomy) was planned 15 days, after the neurosurgical drainage. The mastoid cavity and middle ear were filled with granulation and epithelial desquamation. Furthermore, the ossicles were missing. We removed the cholesteatoma in the mastoid cavity and the tegmental area. There were no bony defects of the facial nerve canal or the semi-circular canal.

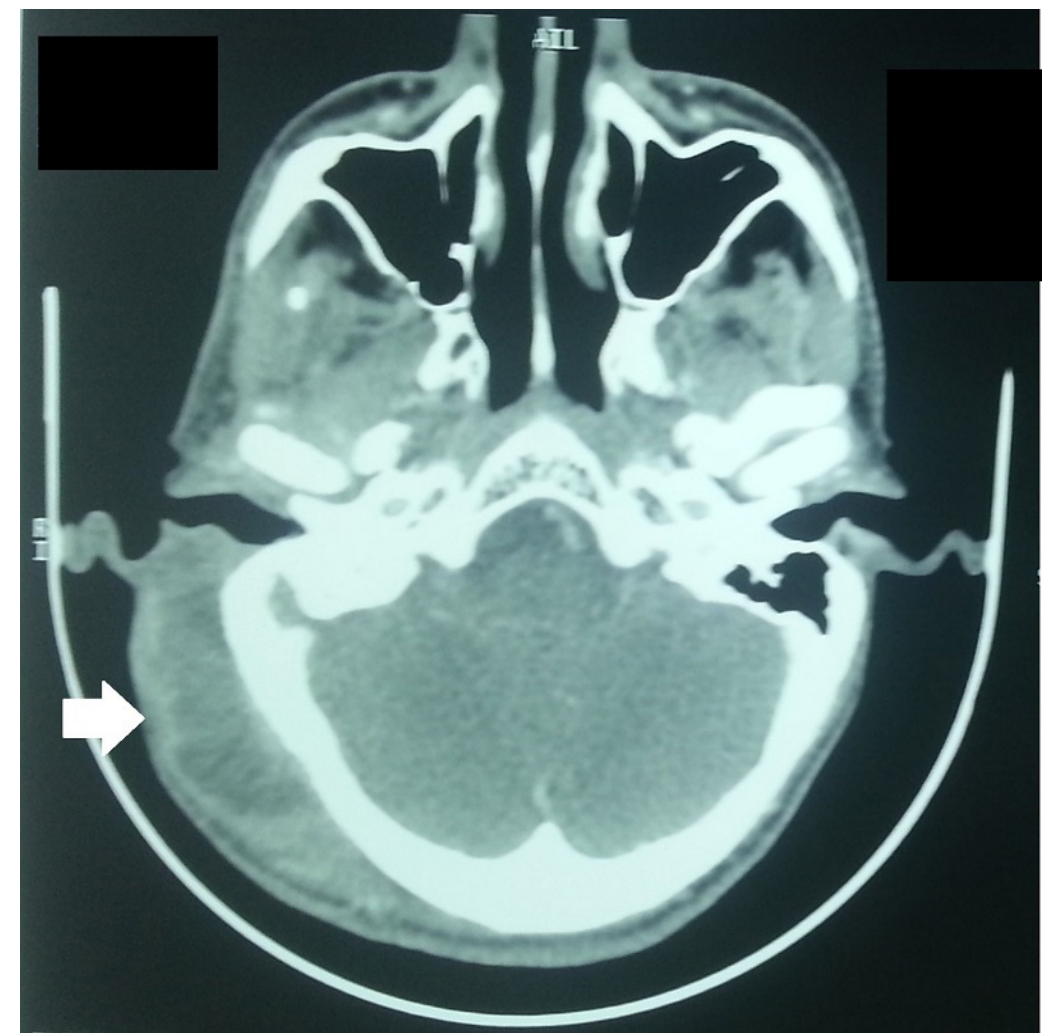

Figure 1: Axial CT revealed a huge subperiosteal abscess in the right postauricular area

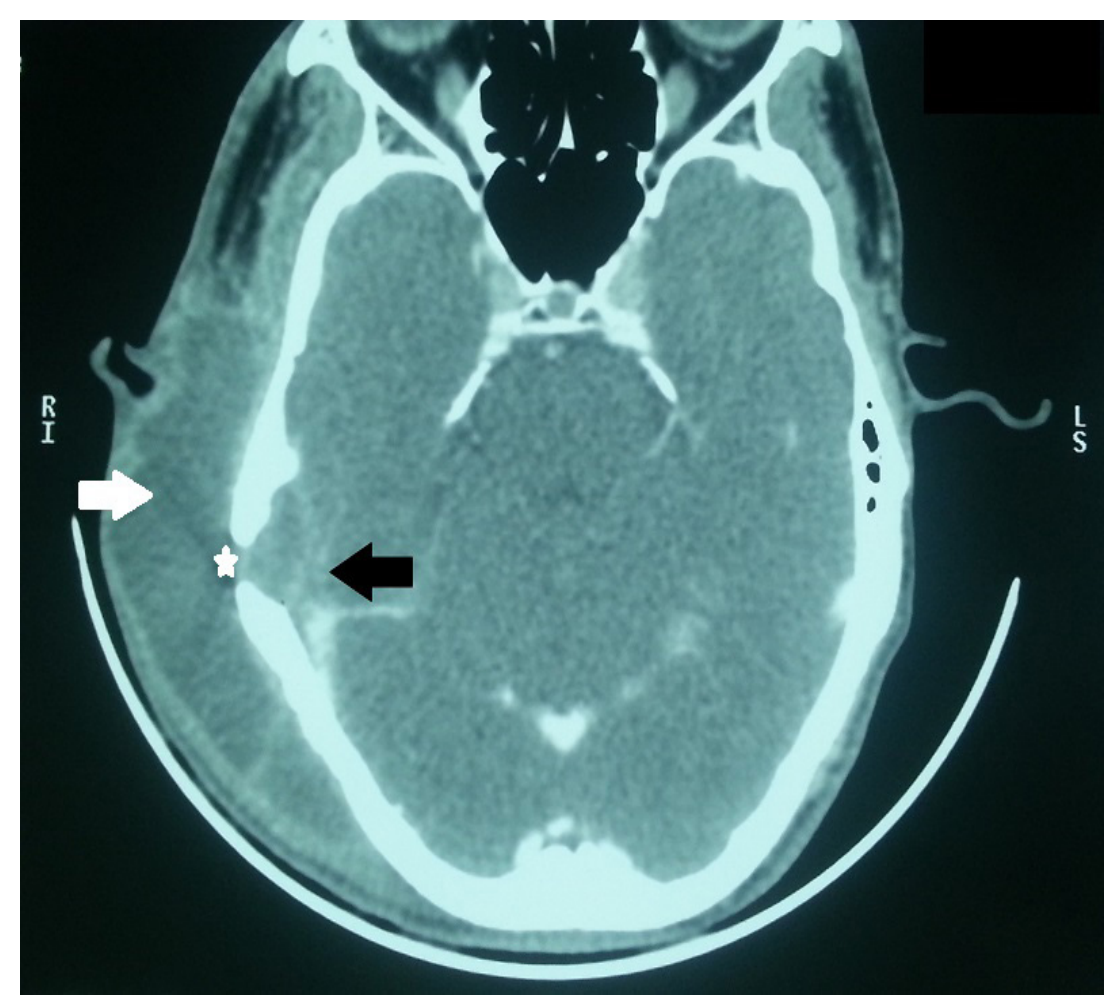

Figure 2: Axial CT (bone window) revealed subdural abscess at the right temporal area (black arrow) in communication with right subperiosteal abscess (white arrow) associated with a bony defect at the right temporal bone (asterisk) 


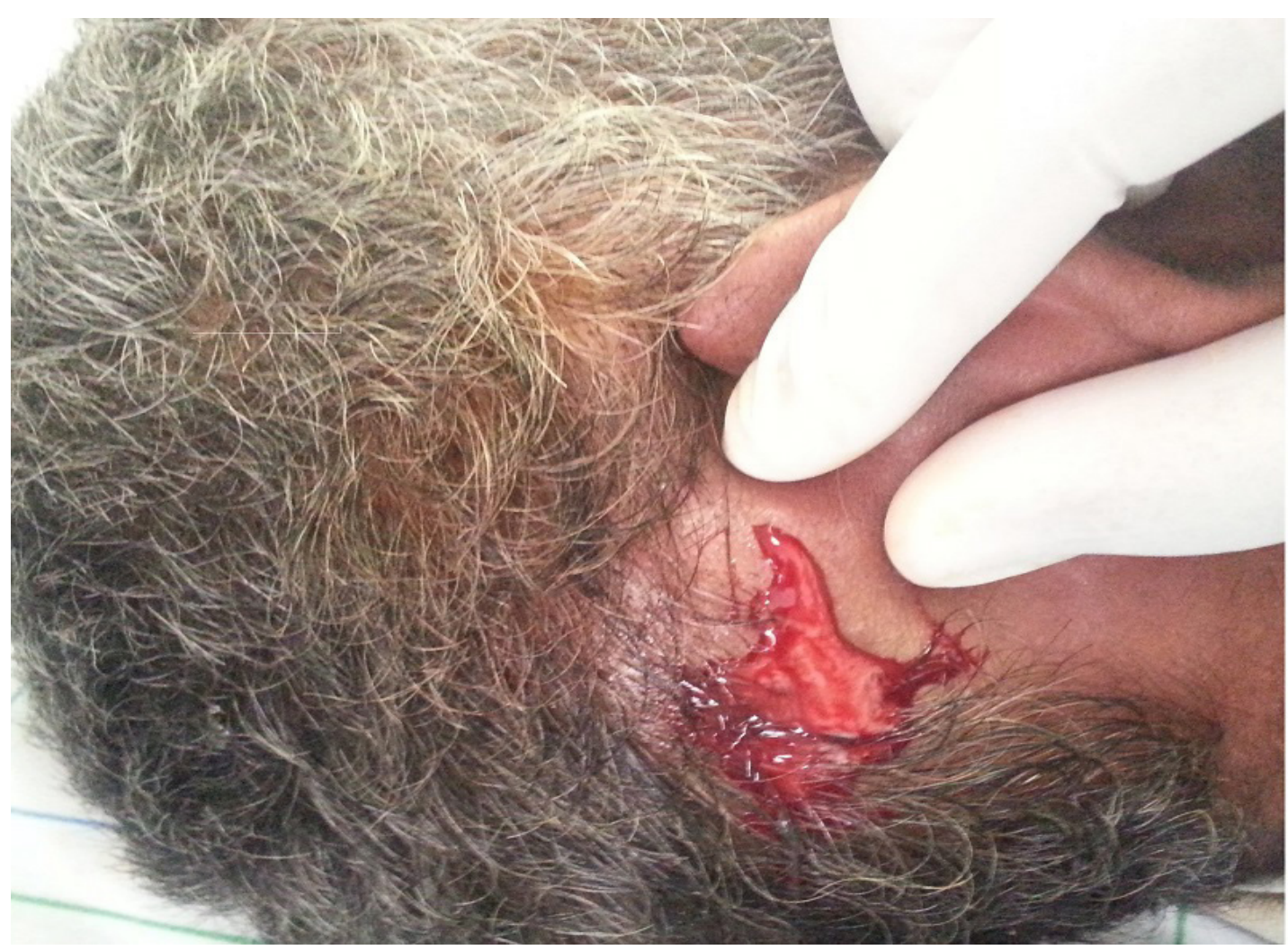

Figure 3: Drainage of mastoiditis under local anesthesia

Post-operative period was uneventful. After mastoidectomy, intravenous antibiotic therapy was maintained for 4 weeks. The right extra axial collection had disappeared on cerebral CT scan (Figure 4) one month after the neurosurgical drainage. He has been under observation as an outpatient for 1 year already and has presented no abnormal signs.

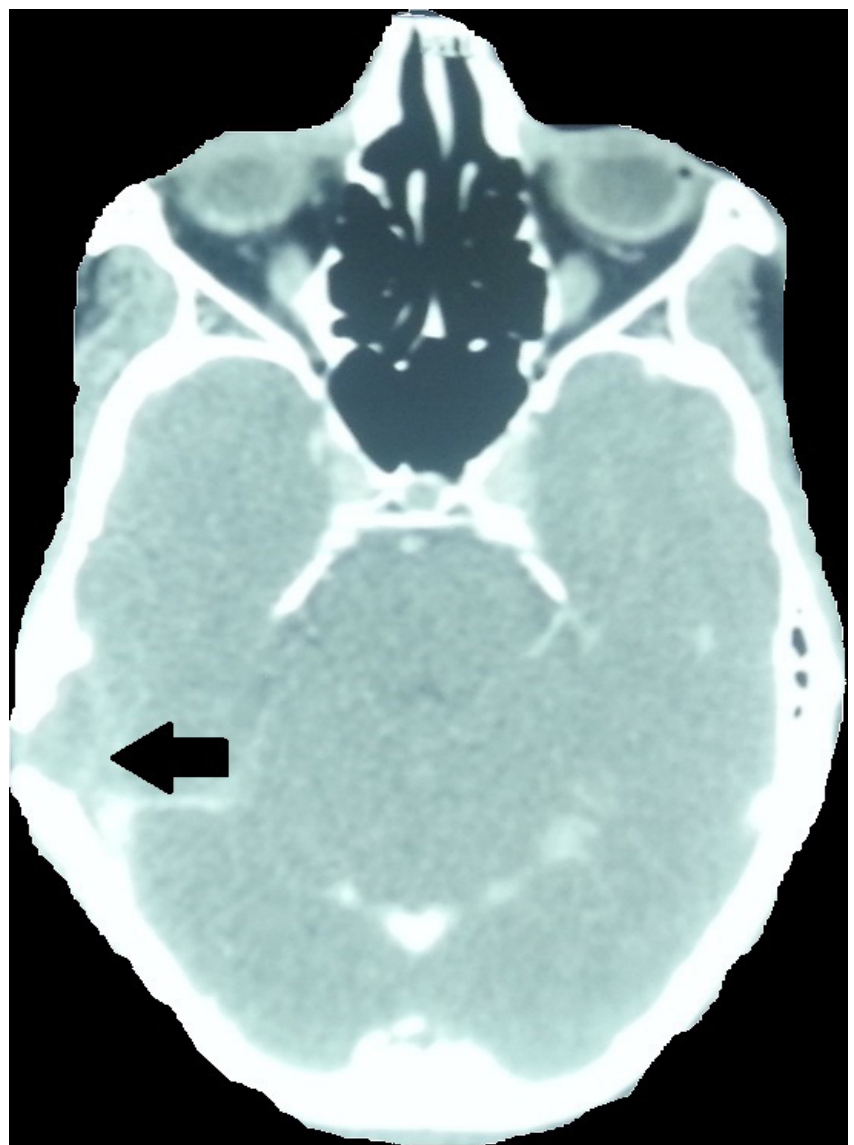

Figure 4: Postoperative axial CT scan of the patient showing total disappearance of brain abscess one month after surgery (low quality) 


\section{Discussion}

The complications of chronic otitis media are divided into extracranial complications (such as mastoiditis, subperiosteal abscess, facial paralysis, and labyrinthitis) and intracranial complications (such as cerebral, sub or extradural abscess, meningitis, focal encephalitis, lateral sinus thrombosis, and otic hydrocephalus) [4-5].

Mastoiditis has been considered as an extracranial complication of otitis media when patients develop tender post-auricular swelling. In the past 20 years, mastoiditis is on the rise again probably due to the growth of antibiotics-resistant bacteria [3-6]. The current estimates of the incidence of mastoiditis are 1.2-3.8 per 100000 children and rates of intracranial complication are generally $5-15 \%$ of cases of acute mastoiditis [7].

When the mastoiditis extends into the subperiosteal space, over the mastoid cortex, it's became a subperiosteal Abscess. This extension most commonly occurs as a result of erosion of the cortex secondary to acute or coalescent mastoiditis, but can also occur as a result of vascular extension secondary to phlebitis of the mastoid veins [8].

Clinically, the disease may be suspected through its characteristic features of injected bulging tympanic membrane, persistent otalgia and fever despite oral antibiotics eventually advancing to postauricular swelling, erythematous change, and tenderness [9]. Moreover, the patients with intracranial complications of mastoiditis may present with slowly developing neurologic symptoms (nonclassic otologic signs and symptoms) such as headache, nausea, vomiting, obtunded consciousness [10].

When the diagnosis is not certain on clinical evaluation, a contrasted CT scan of temporal bone can demonstrate abscess and possibly the cortical defect in the mastoid. Furthermore, the CT scan rules out other possible complications such lymphadenopathy, superficial abscess, and an infected sebaceous cyst [11]. On the other hand, chronic otitis media is responsible for osteitis and breach caused in the tegmen plate, sinus plate gives a way to microorganisms to spread the infection into dura, meninges and temporal lobe of the brain [12]. As a result, meningitis is still the most common complication followed by intra cranial abscess and lateral sinus thrombosis [13]. Sennaroglu et al. highlight the important role of radiologic modalities in diagnosing of intracranial complication. Even more, the early diagnosis is more important than the surgical approach itself [1]. In this case, Staphylococcus aureus is detected in bacterial culture. It exists on the surface of the skin. These bacteria might invade the middle ear and the brain. Hafidh, et al. showed that anaerobes are the most common organisms isolated from brain collection followed by Staphylococcus, Proteus mirabilis and Pseudomonas [14]. Sennaroglu et al., reported that Proteus was identified in 41\%, follow by Streptococcus in $8 \%$ and in the last Staphylococcus in $6 \%$ in his study [1].

Neurosurgical drainage through an open craniotomy with drainage or excision, or by stereotactic aspiration through a burr hole; is the treatment of choice for intracranial collections [15]. The treatment of otogenic origine is indispensible [16]. There is disagreement about the timing and the method of surgical intervention between neurosurgical drainage and mastoidectomy [17]. According to Singh et al. [17] and Murthy et al. [18] first neurosurgical drainage should be done, and later in the same setting mastoidectomy should be done because the mental state becomes worse, and the mortality of otogenic intracranial complications will increase. On the other hand, the advantages of immediate otologic surgery with evacuation of the abscess through the mastoid cavity were suggested by Kurien et al. [19], because at the same time, it treated the complication and removes the source of infection. Samuel, et al. suggested that the otologic and neurosurgical operations performed together or done independently have the same therapeutic outcomes [20]. In this case, neurosurgical drainage was indicated because the subdural empyem size was important and the level of consciousness gradually was worsened. In the addition, simple mastoidectomy was sufficient to eradicate the primary source of the infection.

Generally, after surgical intervention, intravenous antibiotics must be continued for several weeks and serial CT scans with contrast should be to control resolution of the collection $[8,15]$. Both the otologist and neurosurgeon should be vigilant to control any worsening of clinical signs making repeat interventions are required.

\section{Conclusion}

The authors report an uncommon case of intracranial and extracranial complications secondary to middle ear cholesteatoma. Symptoms were indicative of intracranial and extracranial complications. CT revealed middle ear cholesteatoma and disclosed the presence of the subdural abscess. The cholesteatoma and the subdural abscess were treated by surgical interventions. The intracranial complications are potentially serious pathologic in the field of otology.

\section{References}

1. Sennaroglu L, Sozeri B (2000) Otogenic brain abscess: review of 41 cases. Otolaryngol Head Neck Surg 123: 751-5.

2. Palva T, Virtanen H, Mäkinen J (1985) Acute and latent mastoiditis in children. J Laryngol Otol 99: 127-36.

3. Benito MB, Gorricho BP (2007) Acute mastoiditis: increase in the incidence and complications. Int J Pediatr Otorhinolaryngol 71: 1007-11.

4. Verhoeff M, van der Veen EL, Rovers MM, Sanders EA, Schilder AG (2006) Chronic suppurative otitis media: a review. Int J Paediatr Otorhinolaryngol 70: 1-12.

5. Leskinen K, Jero J (2005) Acute complications of otitis media in adults. Clin Otolaryngol 30: 511-6. 
6. Migirov L, Yakirevitch A, Kronenberg J (2005) Mastoid subperiosteal abscess: a review of 51 cases. Int J Pediatr Otorhinolaryngol 69: 1529-33.

7. Ghaffar FA, Wordemann M, McCracken GH Jr (2001) Acute mastoiditis in children: a seventeen-year experience in Dallas, Texas. Pediatr Infect Dis J 20: 376-80.

8. Harker LA, Shelton C (2005) Complications of temporal bone infections Cummings otolaryngology head and neck surgery (4 ${ }^{\text {th }}$ edn) Philadelphia: Elsevier Mosby.

9. Vera-Cruz P, Farinha RR, Calado V (1999) Acute mastoiditis in children--our experience. Int J Pediatr Otorhinolaryngol 50: 113-7.

10. Leskinen K (2005) Complications of acute otitis media in children. Curr Allergy Asthma Rep 5: 308-12.

11. Hashisaki GT (2000) Complications of chronic otitis media The ear: comprehensive otology, Lippincott Williams \& Wilkins Publications, Philadelphia, USA.

12. Dubey SP, Larwin V (2007) Complications of chronic suppurative otitis media, and their management. Laryngoscope 117: 264-7.

13. Kangsanarak J, Navacharoen N, Fooanant S, Ruckphaopunt K (1995) Intracranial complications of suppurative otitis media: 13 years' experience. Am J Otol 16: 104-9.

14. Hafidh MA, Keogh I, Walsh RM, Walsh M, Rawluk D (2006) Otogenic intracranial complications. A 7-year retrospective review. Am J Otolaryngol 27: 390-5.

15. Smith JA, Danner CJ (2006) Complications of chronic otitis media and cholesteatoma. Otolaryngol Clin North Am 39: $1237-55$.

16. Lu CH, Chang WN, Lui CC (2006) Strategies for the management of bacterial brain abscess. J Clin Neurosci 13: 979-85.

17. Singh B, Maharaj TJ (1993) Radical mastoidectomy: its place in otitic intracranial complications. J Laryngol Otol 107: 1113-8.

18. Murthy PS, Sukumar R, Hazarika P, Rao AD, Mukulchand, et al. (1991) Otogenic brain abscess in childhood. Int J Pediatr Otorhinol 22: 9-17.

19. Kurien M, Job A, Mathew J, Chandy M (1998) Otogenic intracranial abscess: concurrent craniotomy and mastoidectomy changing trend in a developing country. Arch Otolaryngol Head Neck Surg 124: 1353-6.

20. Samuel J, Fernandes CM, Steinberg JL (1986) Intracranial otogenic complications: a persisting problem. Laryngoscope 96: 272-8.

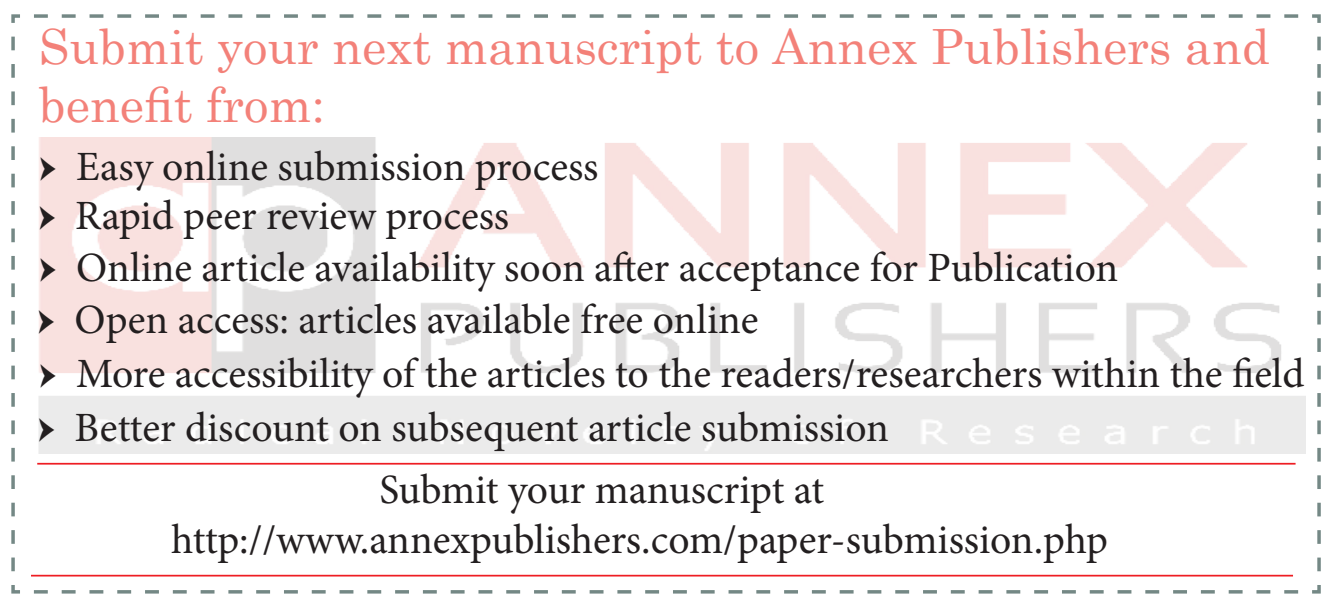

